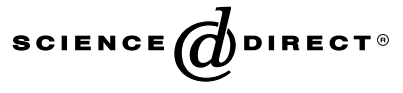

Transportation Research Part D 10 (2005) 127-151
TRANSPORTATION

RESEARCH

PART D

www.elsevier.com/locate/trd

\title{
What if you live in the wrong neighborhood? The impact of residential neighborhood type dissonance on distance traveled
}

\author{
Tim Schwanen $^{\mathrm{a}, *}$, Patricia L. Mokhtarian ${ }^{\mathrm{b}}$ \\ ${ }^{a}$ Faculty of Geosciences, Urban and Regional Research Center Utrecht (URU), Utrecht University, \\ P.O. Box 80.115, 3508 TC Utrecht, Netherlands \\ ${ }^{\mathrm{b}}$ Department of Civil and Environmental Engineering, Institute of Transportation Studies (ITS), \\ University of California, Davis, CA 95616, USA
}

\begin{abstract}
While urban form in general and density in particular are believed by many to significantly influence travel behavior, various recent studies have argued that the true determinants of travel patterns are attitudes rather than land use characteristics. This research builds on this notion and investigates to what extent a lack of congruence between physical neighborhood structure and preferences regarding land use near one's home location (termed 'residential neighborhood type dissonance' or mismatch) affect distance traveled overall and by mode. A conceptual model is described in which the relationship between neighborhood type dissonance and distance traveled is embedded in a wider set of individual and household choices, and tobit models of the influence of neighborhood type mismatch are presented. The results suggest that neighborhood type mismatch should be taken into account in future research as well as in policies attempting to modify travel behavior through land use regulations.
\end{abstract}

(c) 2004 Elsevier Ltd. All rights reserved.

Keywords: Distance traveled; Land use; Attitudes; Tobit analysis; San Francisco Bay Area; Residential self-selection

\footnotetext{
* Corresponding author. Tel.: +31 3025344 37; fax: +31 302532037.

E-mail addresses: t.schwanen@geog.uu.nl (T. Schwanen), plmokhtarian@ucdavis.edu (P.L. Mokhtarian).
} 


\section{Introduction}

Of all dimensions of urban form that have been hypothesized to affect individual travel behavior, population density is probably the one for which the least ambiguous results have been found. Higher densities tend to be associated with shorter distances traveled, particularly by car, and hence with lower per capita consumption of non-renewable energy and emissions of pollutants (Pushkarev and Zupan, 1977; Cervero, 1996; Stead, 2001). When explaining these findings, the usual argument is that in higher-density settings (potential) origins and destinations are typically closer to one another, which limits the need to travel and makes walking/bicycling more attractive. The concentration of travel demand in high-density environments also makes it easier to provide frequent transit services, which stimulates transit patronage. At the same time, this concentration of travel demand results in road congestion and parking problems that reduce the attractiveness of the automobile.

These findings have been qualified by pointing out that the associations observed between density and travel distance may not reflect true causality. Kitamura et al. (1997) suggest that attitudes toward travel and land use may be the real determinants of travel distance and residential location. This implies that residential self-selection processes are underlying the association between travel and land use: households with an affinity for walking and/or traveling by transit may ceteris paribus choose to reside in a high-density neighborhood exactly because such a location facilitates walking or using transit. Using structural equations modeling, Bagley and Mokhtarian (2002) provide further evidence for this line of reasoning. Other studies have supported the notion that residential location choice is endogenous to the relations between travel and land use (e.g., Boarnet and Crane, 2001; Sermons and Seredich, 2001; Krizek, 2003).

If attitudes toward land use and travel rather than land use characteristics are more important determinants of travel behavior, this has implications for policymaking. At its most extreme, it suggests that land use policies can only contribute to a reduction of auto driving and its attendant environmental impacts, if high-density neighborhoods attract households without a strong affinity for auto travel. Policies that only seek to provide land use conditions favorable to non-auto modes may thus not be sufficient; they may need to be supplemented with other measures to disproportionately attract the appropriate type of households to a high-density location.

To gain further insight into the relative importance of attitudes toward travel and land use visà-vis physical land use conditions, the concept of residential neighborhood type dissonance is introduced. This is defined as a lack of congruence between the land use characteristics of the neighborhood where the individual currently resides and preference structures toward such characteristics (Schwanen and Mokhtarian, 2004). The aim of the paper is twofold: First, it will assess the impact of residential neighborhood type dissonance on distance traveled overall as well as by transport mode. Second, it will examine to what extent the relationships between dissonance and distance traveled are altered once other factors known to influence distance traveled are taken into account, in particular sociodemographics, personality, lifestyle, mobility limitations, and travelrelated attitudes. Data stem from commuters in three neighborhoods in the San Francisco Bay Area: the urban neighborhood of North San Francisco and the suburbs of Concord and Pleasant Hill. 


\section{Conceptual framework}

The analysis is based on the notion that travel choices are embedded hierarchically in a wider set of choices (Salomon and Ben-Akiva, 1983): daily or weekly travel choices are conditioned by medium-term mobility choices regarding the location of the residence and workplace, auto ownership and commute mode, that are in turn conditioned by long-term lifestyle choices with respect to family, employment and leisure. Fig. 1 conceptualizes daily or weekly travel choices as depending on residential location and vehicle availability, ${ }^{1}$ as well as choices and attitudes with respect to family, employment, leisure, traveling and land use. We have added the concept of residential neighborhood type dissonance, which points to a friction between long- and medium-term choices regarding land use, in the choice hierarchy of Fig. 1. A person is considered dissonant or mismatched if the current residential neighborhood does not coincide with her preferences regarding land use. A state of dissonance may be resolved through relocation or through adjustment of individuals' orientation toward land use (Schwanen and Mokhtarian, 2004). Such adaptations may take time, and differences may be observed in travel behavior between dissonant and consonant inhabitants of different types of neighborhoods.

Two inferences about the associations between residential self-selection and travel behavior can be made from the figure: First, the process of residential self-selection and its impacts on travel is driven by travelers' attitudes, which we assume to be relatively stable over time (although feedback effects from short-term travel behavior are certainly possible). Hence, attitudinal variables are included explicitly when analyzing residential self-selection processes. Second, a wide set of attitudinal variables would seem to influence the interdependence of residential location and travel choices. Discussions about residential self-selection effects concerning travel behavior have evolved mostly around mode choice (Cervero and Duncan, 2002; Handy, 1996), suggesting that it is relevant to consider attitudes centered on specific modes. While we readily acknowledge the potentially important role of mode-related attitudes, it is hypothesized that more general travel attitudes and especially land use preferences are also integral to the interdependence of residential location and travel choices.

The main hypothesis tested is that distances traveled overall and by mode differ between consonant and dissonant residents of both urban (or higher-density) and suburban (or lower-density) neighborhoods. Distinguishing travelers currently living in urban and suburban neighborhoods, and travelers with urban and suburban land use preferences, we can construct four types of travelers:

- True urbanites: urban residents with urban land use preferences.

- Mismatched or dissonant urban dwellers: urban residents with suburban land use preferences.

- Mismatched or dissonant suburban dwellers: suburban residents with urban land use preferences.

- True suburbanites: suburban residents with suburban land use preferences.

\footnotetext{
${ }^{1}$ Ideally workplace location and commute mode choice should be added to this block. However, because the data did not include formal questions pertaining to those choices to reduce the response burden on participants, commute mode and length and workplace location are not considered here. Schwanen and Mokhtarian (2005) nevertheless deduced a primary commute mode from the data, but this was primarily derived from questions about distance traveled by various modes. Inclusion of that variable as an explanatory factor here would be tautological.
} 


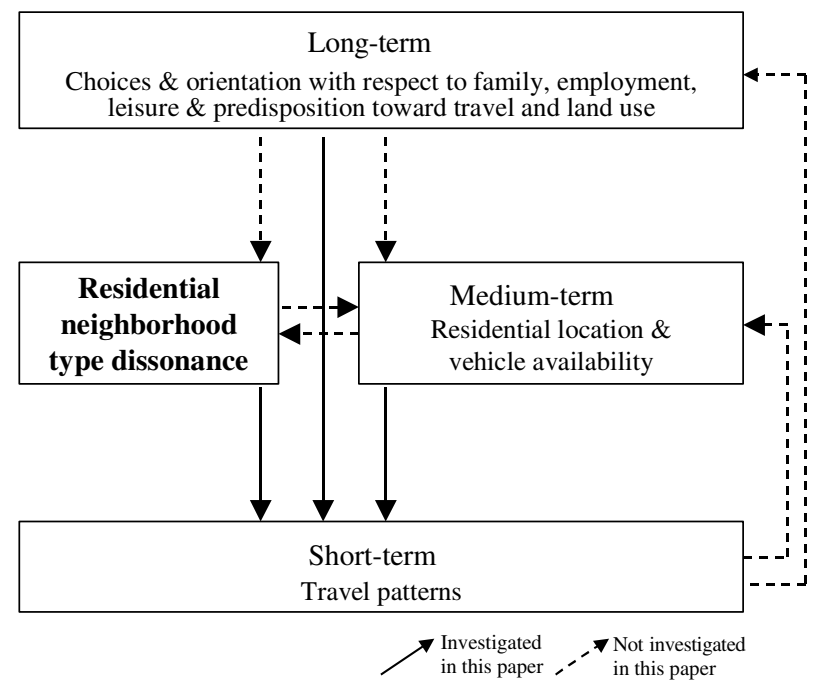

Fig. 1. Conceptual scheme.
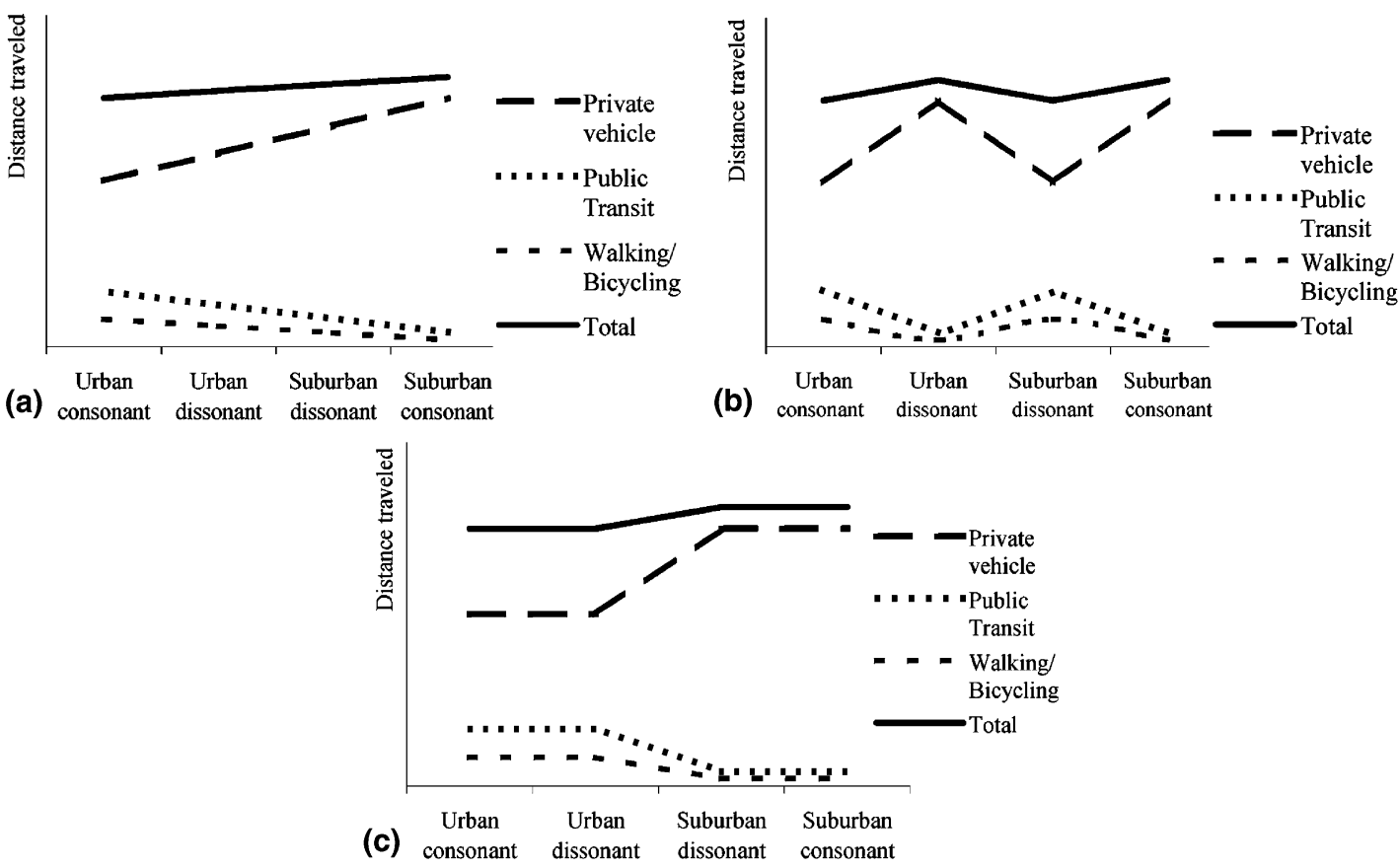

Fig. 2. Hypothesized impacts of residential neighborhood type dissonance on distance traveled overall and by transportation mode: (a) physical land use structure and land use preferences equally important, (b) only land use preferences important, (c) only land use physical structure important.

If land use preferences and the current residential neighborhood affect distance traveled to the same degree, we may observe the differences seen in Fig. 2a. However, if a situation as in Fig. 2b 
or $\mathrm{c}$ is observed, this suggests that land use preferences or the physical structure of land use surrounding the dwelling, respectively, dominate the explanation of differences in distance traveled. Fig. 2b (as well as, to a lesser extent, Fig. 2a) suggests that residential self-selection is important and should be taken into account when studying the relationship between land use and travel. With its large within-neighborhood differences, Fig. $2 b$ also indicates that the physical structure of land use is not equally relevant to its inhabitants. If, however, the situation resembles Fig. 2c, the physical properties of neighborhoods exert a strong conditioning influence on travel distance and are far more important than individual preferences toward land use. Of course, with its focus only on dissonance and the built environment of the residential neighborhood, Fig. 2 is very much a simplification of reality and when evaluating the role of neighborhood type dissonance on distance traveled other determinants of travel distance also need to be included (Fig. 1).

\section{Methodological approach}

The traveler's decision process with respect to travel distance can be seen as comprising two decisions: the decision to engage in travel, and the conditional decision about the number of miles. Consequently, the distribution of observed travel distances for a sample of travelers is truncated at zero. Although the standard tobit model has been designed specifically for such variables (McDonald and Moffitt, 1980), this model structure assumes that the same variables affect both the engagement decision and the conditional decision about the actual mileage. This assumption may be too restrictive, because the probability of traveling by bus, for instance, may depend on different factors than the decision about the actual mileage by that mode. A solution is the use of a tobit model correcting for selectivity bias (Kitamura, 1984; Greene, 2002):

$$
\begin{aligned}
& y_{i}^{*}=\beta^{\prime} x_{i}+\varepsilon_{i} \\
& z_{i}^{*}=\alpha^{\prime} w_{i}+u_{i}
\end{aligned}
$$

with

$$
\begin{aligned}
& \operatorname{Corr}[\varepsilon, u]=\rho \\
& y_{i}=0 \quad \text { if } y_{i}^{*} \leqslant 0, \quad y_{i}=y_{i}^{*} \quad \text { if } y_{i}^{*}>0 \\
& z_{i}=0 \quad \text { if } z_{i}^{*} \leqslant 0, \quad z_{i}=1 \quad \text { if } z_{i}^{*}>0 \quad \text { and } \\
& {\left[y_{i}, x_{i}\right] \quad \text { only observed when } z_{i}=1 .}
\end{aligned}
$$

The model consists of two equations, with (1a) being the tobit regression equation and (1b) the probit selection equation. The tobit equation is based on a latent continuous variable $y_{i}^{*}$ that can take on any value. In (1a) $x_{i}$ is a vector of independent variables; $\beta^{\prime}$ a vector of estimable parameters; and $\varepsilon_{i}$ an error term distributed $N\left[0, \sigma_{\varepsilon}^{2}\right]$. The selection equation is also based on a latent continuous variable, $z_{i}^{*}$, reflecting the propensity that individual $i$ has to choose a given mode of transport. This propensity is a function of a set of independent variables $w_{i}$ (some or all of which may overlap with $x_{i}$ ) and associated parameters $\alpha^{\prime}$, and unobserved factors summarized by the error term $u_{i}\left(u_{i} \sim N\left[0, \sigma_{u}^{2}\right]\right)$. The correlation between the unobserved variables in the two equations is given by $\rho$. A statistically significant estimate for $\rho$ indicates that modeling the decisions 


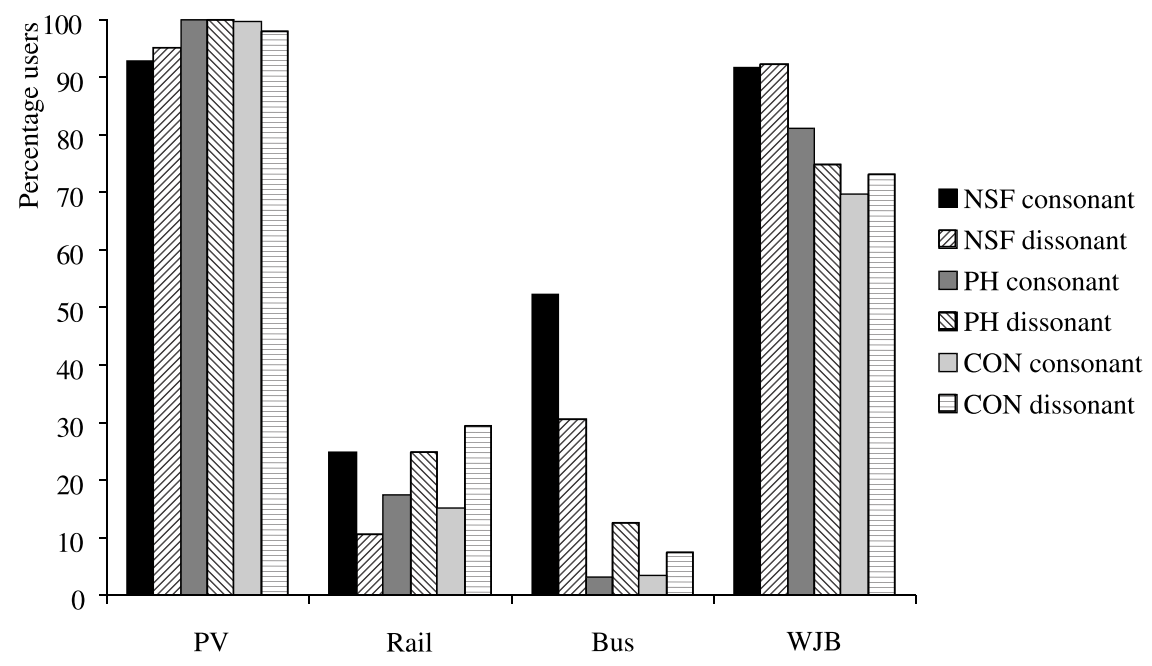

$\mathrm{PV}=$ personal vehicle $\mathrm{WJB}=$ walking/jogging/bicycling $\mathrm{NSF}=$ North San Francisco; $\mathrm{PH}=$ Pleasant Hill $; \mathrm{CON}=$ Concord

Fig. 3. Percentage of respondents using a certain transportation mode, by residential neighborhood and residential neighborhood type dissonance (MM5).

on mode use and distance traveled simultaneously is superior to modeling them separately, which would result in biased coefficients (Bhat, 1997). A ' + ' sign implies that unobserved factors favoring the use of a given mode, say walking, also positively affect the distance covered on foot. Frequently, these unobserved factors are assumed to reflect personality traits or unobserved attitudinal variables. A '-' sign suggests that unobserved factors favoring the use of a given mode, say walking, reduce the distance covered on foot. In this case, the unobserved factors may, for instance, reflect a tendency of variety seeking with respect to mode use: A person may like to travel on different modes and therefore distribute his travel needs and desires among various modes.

In the models for distance traveled by rail, bus, and walking/jogging/bicycling the simultaneous equations system is used. However, regular single-equation tobit modeling is applied to distance traveled overall and by private vehicle because all respondents engage in some travel and almost all of them travel by personal vehicle (see Fig. 3), which makes the estimation of a selection equation for those variables impossible or the results suspicious. ${ }^{2}$

For the regular tobit models, a modified version of the McKelvey-Zavoina statistic is presented as a goodness-of-fit indicator (Veall and Zimmerman, 1994):

$$
R^{2}=\frac{\sum_{i=1}^{N}\left(\hat{y}_{i}^{*}-\hat{y}_{.}^{*}\right)^{2}}{\sum_{i=1}^{N}\left(\hat{y}_{i}^{*}-\hat{y}_{.}^{*}\right)^{2}+N \widehat{\sigma}^{2}}
$$

where $\hat{y}_{i}^{*}=\widehat{\beta}^{\prime} x_{i}$ is the predicted value of the latent variable for the individuals with characteristics $x_{i}, \hat{y}^{*}$ is the mean of $\hat{y}_{i}^{*}$, and $\widehat{\sigma}^{2}$ is the estimated variance of $\varepsilon_{i}$. The numerator of this pseudo- $R^{2}$ is a measure of the explained variance, and the second term in the denominator an indicator of unex-

\footnotetext{
${ }^{2}$ All models are estimated with maximum likelihood estimation in LIMDEP, Version 8.0 (Greene, 2002).
} 
plained variance. Further, likelihood ratio indices are presented for both the regular tobit models and the tobit models correcting for selectivity bias as an indication of model fit. ${ }^{3}$

\section{Data and variables}

The data comprise responses to a 14-page questionnaire collecting information on a variety of travel and related issues. The survey was mailed in May 1998 to 8000 randomly selected households of three neighborhoods in the San Francisco Bay Area. Half were mailed to the urban neighborhood of North San Francisco; the remainder split evenly between the contiguous suburbs of Concord and Pleasant Hill. A randomly selected adult in each household was asked to complete the survey. About 2000 surveys were returned, yielding a response rate of $25 \%$. This is well within the $10-40 \%$ range considered typical for mail surveys of the general population (Sommer and Sommer, 1997). Using Census data, Curry (2000) has verified that the sample of respondents is roughly representative for the population of the neighborhoods studied with respect to gender, although those with more education and higher incomes are overrepresented (which is typical for self-administered questionnaires). Representativeness, however, with respect to marginal distributions of individual variables is not as critical when the purpose of the study is exploring relationships among multiple variables, as is the case here (Babbie, 1998). The subset of 1358 respondents identified as workers commuting at least once a month is used. This restriction of the sample is based on the assumption that attitudes toward travel and residential location differ fundamentally between commuters and non-commuters (Schwanen and Mokhtarian, 2004).

The neighborhoods selected for the survey differ in terms of physical structure and layout (Table 1). North San Francisco is a traditional neighborhood dating back to the late 1800s with a high intensity of land use (reflected in high building densities) and strong mixing of residential and business locations. Homes and lots are small and there is little parking space. In addition, street patterns are rectangular, pedestrian facilities well developed, and the neighborhood is well connected to the public bus system, but poorly accessible by Bay Area Rapid Transit (BART). Concord is more or less the reverse of North San Francisco, being characterized by low levels of land use intensity and diversity, large houses and yards, ample parking space, radiating street patterns, and poor bus service but good access to BART. Pleasant Hill is also suburban, monofunctional and not pedestrian-friendly, but differs in several respects from Concord. Building densities are considerably higher, whereas the connectivity of the cul-de-sac street patterns is lower.

\footnotetext{
${ }^{3}$ For the models correcting for selectivity bias two likelihood indices are presented. The first is defined as 1 minus the quotient of the log likelihood at convergence and the log likelihood for a tobit model with a single constant term. This constant-only tobit model does not correct for selectivity bias; it is a regular tobit model with one constant. This simple constant-only model is used because maximum likelihood estimation is infeasible for a model system consisting of a probit selection equation with only a constant and a tobit equation with only a constant. The second likelihood ratio index applies only to the probit selection model. It is the likelihood ratio index for an independently estimated probit model identical to the probit equation in our model system, and is defined as 1 minus the quotient of the log likelihood at convergence and the log likelihood for the independent probit model with neither variables nor a constant term (an 'equally likely' model). This likelihood ratio index is presented to show that our selection models provide reasonably good insights into the choice whether to use a given mode or not (Ermisch and Wright, 1994). For the regular tobit models only the first likelihood ratio index is provided.
} 
Table 1

Summary of spatial structure indicators for the communities surveyed

\begin{tabular}{|c|c|c|c|}
\hline & North San Francisco & Pleasant Hill & Concord \\
\hline Density & High & Intermediate & Low \\
\hline Business locations & $\begin{array}{l}\text { Throughout the } \\
\text { neighborhood }\end{array}$ & $\begin{array}{l}\text { Central near BART } \\
\text { and Freeway }\end{array}$ & $\begin{array}{l}\text { Western end of the } \\
\text { eighborhood }\end{array}$ \\
\hline $\begin{array}{l}\text { Distance to San Francisco } \\
\text { Central Business District }\end{array}$ & $5 \mathrm{~km}$ & $41 \mathrm{~km}$ & $46 \mathrm{~km}$ \\
\hline Street pattern & Grid & Fragmented & Radiating \\
\hline Topography & Hills & Flat & Flat \\
\hline Freeway access & I-80 $1.5 \mathrm{~km}$ East & I-680 transects the community & $\begin{array}{l}\text { I- } 680 \text { on the western side; } \\
\text { Hwy } 24 \text { transects } \\
\text { the community }\end{array}$ \\
\hline BART access & None & Southeast of neighborhood & West side of the neighborhood \\
\hline Bus lines & 21 Bus routes & 3 Bus routes & 3 Bus routes \\
\hline Sidewalks & Wide & Discontinuous & Discontinuous, missing \\
\hline Walking & Common & Hazardous & Hazardous \\
\hline
\end{tabular}

Source: After Kitamura et al. (1997).

Pleasant Hill and Concord grew rapidly in terms of population and area after the I-680 interstate highway opened in 1964.

The questionnaires collected information on a wide range of variables. The relevant ones can be grouped into: ${ }^{4}$

- Objective mobility: This section of the questionnaire asked about the number of miles traveled for short-distance trips ( $<100$ miles one way) during a typical seven-day week in total, as well as by mode or purpose. The responses were used directly in the descriptive analysis in Section 5. For the tobit models they were transformed by taking the natural logarithm of the distance traveled plus one mile so that zero distances traveled return a value of $\ln (1)=0$. The modes analyzed are the private vehicle (driver/passenger in a car, van, or small truck), rail (regional commuter train, BART, or light rail), bus, and walking/jogging/ bicycling.

- Travel liking: Respondents were asked to rate traveling in general as well as by mode and purpose separately on a five-point scale from 'strongly dislike' to 'strongly like'.

- Attitudes toward travel and land use: Factor analysis was applied to 32 attitudinal statements related to travel, land use and the environment. Respondents were asked to react on fivepoint Likert-type scales ranging from 'strongly disagree' to 'strongly agree'. Six underlying dimensions were identified, using principal-axis factoring with oblique rotation: travel dislike, pro-environmental policy, commute benefit, travel freedom, pro-high density, and travel stress factors. The pro-high density factor is particularly important. It represents the following statements (pattern matrix loading in parentheses): 'Living in a multiple family unit would not give me enough privacy' $(-0.62)$; 'I like living in a neighborhood where

\footnotetext{
${ }^{4}$ Mokhtarian et al. (2001) and Redmond (2000) provide more detailed descriptions of these sets of variables.
} 
there is a lot going on' (0.49); 'Having shops and services within walking distance from my home is important to me' (0.40); and 'I like to have a large yard at my home' (-0.32). A high score on this attitudinal dimension thus suggests a strong preference for high-density living.

- Lifestyle: Respondents' reactions to 18 Likert-type statements relating to work, family, money, status and the value of time were factor-analyzed. This yielded four dimensions: status seeker, workaholic, family/community-oriented, and frustration factors.

- Personality: Respondents were asked to indicate how well each of 17 words/phrases applied to them on a five-point scale ranging from 'hardly at all' to 'almost completely'. The responses were factor-analyzed and reduced to four underlying dimensions: the adventure seeker, organizer, loner, and the calm personality.

- Mobility constraints: These variables refer to physical or psychological limits on travel. They are measured by questions about the existence of physical or psychological conditions that restrict traveling by certain modes and/or at certain times of day with ordinal response categories 'no limitations', 'limits how often/long', and 'absolutely prevents'.

- Sociodemographics: The survey included an extensive list of questions about sociodemographic characteristics to allow for comparison to other surveys and because numerous studies have identified their relevance to travel behavior. The sociodemographic variables include age, gender, education level, income, and the number of persons in the household together with their age group and employment status. These were used to construct a typology of households (Schwanen and Mokhtarian, 2004): single worker; two-worker couple; one-worker couple; multiple-worker $(\geqslant 2)$ family; one-worker family; multiple $(\geqslant 3)$ working adults; 'other' households. Couple households consist of two adults. Families also consist of two adults but further include at least one child ( $\leqslant 17$ years). Multiple working adults households comprise three or more adults, at least two of whom are employed. The sociodemographics section of the survey also includes questions about the residential neighborhood and vehicle availability. The latter is operationalized by the ratio of personal vehicles to persons with a valid driver's license in the household.

Using variables captured from the questionnaire, Schwanen and Mokhtarian (2004) derived five measures of the incongruence with respect to land use features between the current neighborhood type and an individual's preference toward such characteristics. Five measures were proposed instead of one, because it was deemed too difficult to combine several demands a measure of dissonance should meet in a single indicator. These demands implied among others that the indicators should give a straightforward assessment of the presence of mismatch in a neighborhood, while at the same time reflect subtle differences in the extent of dissonance across individuals in that neighborhood. All five measures are, however, based on the same principle: the respondents' score on the standardized pro-high density factor (as a preference indicator) is contrasted with the type of neighborhood in which they currently reside.

The five measures can be summarized as follows (Table 2). MM1 is a binary indicator with a value of one indicating that a respondent is mismatched. Roughly speaking, an urban resident is classified as dissonant if s/he has a negative value on the pro-high density factor, and a suburban resident when s/he has a positive score. The appeal of MM1 is that it produces a straightforward estimate of the level of mismatch in a neighborhood. Its disadvantage is, however, that 
Residential neighborhood type dissonance indicators and scores by neighborhood (after Schwanen and Mokhtarian, 2004)

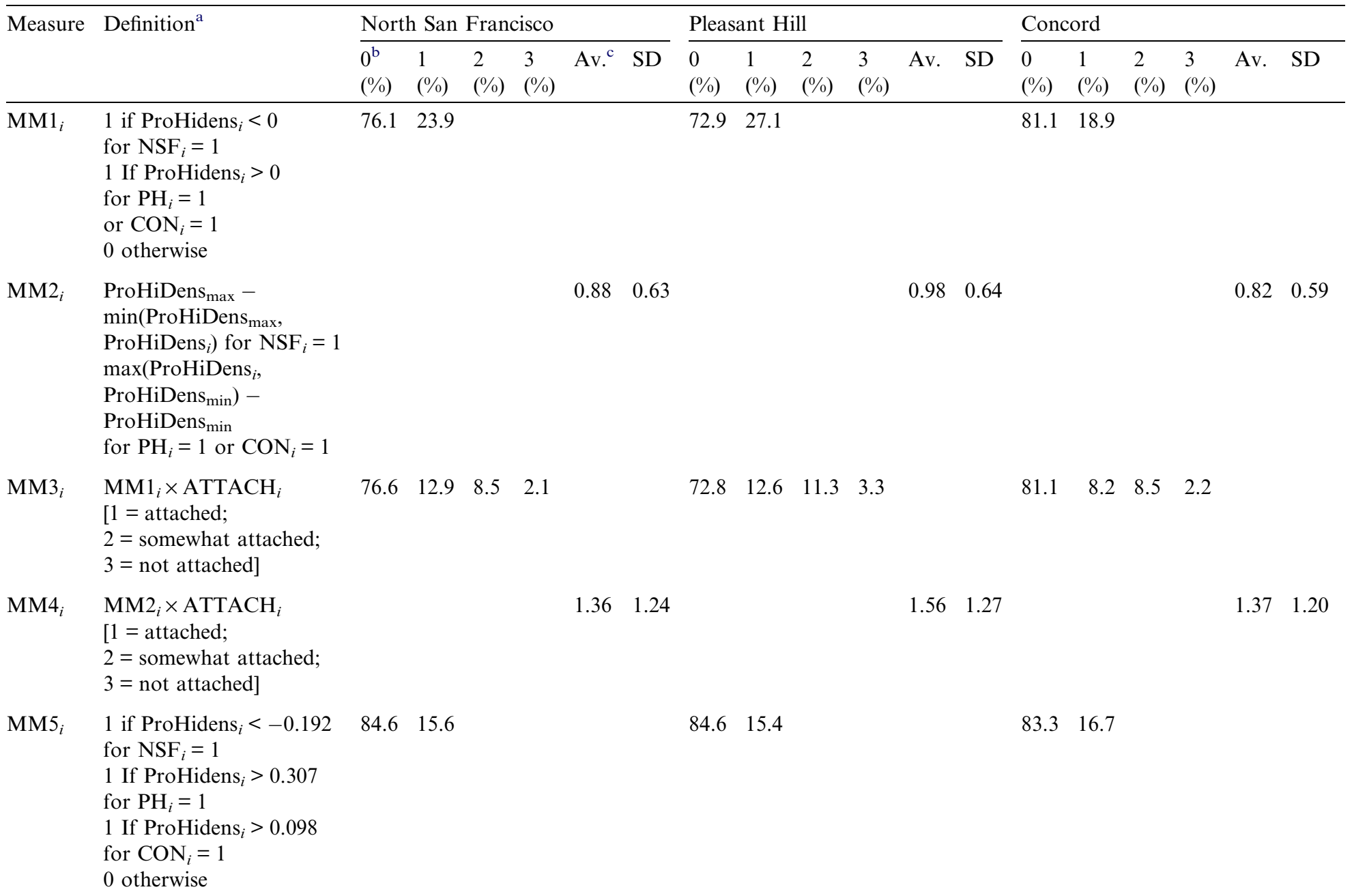

${ }^{a}$ Subscript $i$ denotes an individual respondent; 'ProHidens' stands for pro-high density factor, 'ATTACH' for the level of attachment to the current neighborhood, 'NSF' for North San Francisco, 'PH' for Pleasant Hill, and 'CON' for Concord.

${ }^{\mathrm{b}}$ Interpretation of discrete scores: $0=$ consonant; $1=$ dissonant; $2=$ more dissonant; $3=$ most dissonant.

c 'Av.' stands for average, and 'SD' for standard deviation. 
it ignores differences in the degree of dissonance. Therefore MM2 has been devised, which is defined for an urban resident as the maximum score on the pro-high density factor across the whole sample minus the respondent's real score, and similarly (in reverse) for suburban residents. ${ }^{5}$

Because we believed neighborhood type dissonance to be linked with the extent to which a respondent feels attached to her current neighborhood, we defined two further mismatch indicators, MM3 and MM4. These are interactions of MM1 and MM2 with an ordinal indicator of the level of attachment $(1=$ attached; $2=$ somewhat attached; $3=$ not attached $)$, and thus reflect the notion that the level of neighborhood type dissonance is exacerbated by a lack of attachment to the current neighborhood. Finally, MM5 was intended as a very conservative dissonance indicator, devised to prevent potential misclassification of residents as mismatched as much as possible. Urban (suburban) residents are considered dissonant only if their pro-high density factor score is extremely low (high) compared with the neighborhood average, i.e. a score that is lower (higher) than the neighborhood average minus (plus) one standard deviation.

Although we feel these measures provide meaningful insights when related to observed travel patterns, we readily acknowledge various shortcomings. For instance, attention is only focused on the physical attributes of the neighborhood but not to social characteristics (the neighbors) or dwelling features. This one-dimensional perspective may affect the results: persons who are now classified as mismatched may in fact be perfectly consonant on the social dimension or occupy a dwelling that optimally matches their preferences. We focused on land use characteristics primarily because of data limitations, although one might also argue that it is most likely physical neighborhood attributes that affect travel behavior. Data limitations also prevent the consideration of changes in the level of dissonance over time or the effect of a person's residential history.

Analysis of the presence (MM1) and level (MM2) of dissonance by neighborhood indicates that Pleasant Hill residents are most and Concord residents least mismatched (Table 2). For MM3 and MM4 a similar picture emerges, although North San Francisco and Concord have the same score for the latter. Note that, as a consequence of its definition, the presence of mismatch reflected by MM5 is about $16 \%$ in all neighborhoods. To account for neighborhood-specific variations in dissonance, we have analyzed its impact on travel distance separately for each neighborhood in the descriptive and tobit analyses below.

The impact of residential neighborhood dissonance on distance traveled is embedded in a wider web of causal links, as shown in Fig. 1. Two types of models have hence been specified. Baseline models have the log miles traveled (overall and by mode) as dependent variables and neighborhood dummy variables and mismatch indicators by neighborhood as determinants. These models isolate the impact of mismatch on distance traveled and therefore show it in the strongest and most direct way. Yet, because they omit other variables likely to influence distance traveled, they tend to overstate the influence of mismatch. To take other factors into account, full models have

\footnotetext{
${ }^{5}$ The maximum (minimum) score for urban (suburban) cases were not used, but the 95th (5th) percentile score to make this indicator less sensitive to outliers. Scores more extreme than the 95th (5th) percentile were set equal to the cutoff point, so that MM2 is always zero or positive.
} 
been specified, which also include vehicle availability (ratio of vehicles to persons with a valid driver's license), sociodemographics, mobility limitations, personality and lifestyle, and travel-related attitudes as explanatory variables. These variables may influence distance traveled not only directly, but also indirectly through their impact on the extent of neighborhood type dissonance (Schwanen and Mokhtarian, 2004). ${ }^{6}$ Unfortunately, these direct and indirect impacts cannot be separated from one another with the tobit models employed. This may imply that the influence of neighborhood type dissonance on distance traveled is understated in the full models. To a certain extent then the basic and full models indicate the upper and lower bounds on the importance of dissonance to the explanation of differences in distance traveled.

\section{Descriptive analysis}

As expected, respondents living in North San Francisco travel fewer miles in total than those in Pleasant Hill and Concord. However, neither the variables representing whether a respondent is mismatched or not (MM1 and MM5), nor those measuring the degree of dissonance (MM2, MM3, and MM4) are statistically significantly related to total miles traveled in North San Francisco and Pleasant Hill (Table 3). The only statistically significant difference (at $p=0.090$ ) can be found for MM3 in Concord, but this is due to the somewhat unusual behavior of the seven respondents falling in the most dissonant category there. In short, residential neighborhood type dissonance does not appear to be strongly relevant to the total distance traveled, as far as these descriptive results are concerned.

Yet, if we consider distance traveled per transportation mode, we do find a number of statistically significant differences between consonant and dissonant residents for each neighborhood. Table 4 summarizes the results of within-neighborhood bivariate analyses of the relationships between neighborhood type dissonance and distance traveled per mode. For the discrete value indicators MM1, MM3 and MM5 the average distance has been calculated for each dissonance category; $t$-tests and Kruskal-Wallis tests have been conducted to assess whether differences in those mean values are statistically significant. Bivariate correlation coefficients have been calculated to quantify the relationships between distance and the continuous mismatch indicators MM2 and MM4.

Statistically significant relations between distance and neighborhood type dissonance mostly occur for North San Francisco residents. The average weekly distance by private vehicle tends to be higher among dissonant residents of that neighborhood (MM2 and MM3). At the same time, distance by rail and bus is lower as the level of dissonance reflected by MM2, MM3 and MM4 is higher for North San Francisco residents. For the distance by bus the effect of mismatch is also statistically significant for the binary indicators MM1 and MM5. Finally, the distance by walking/jogging/bicycling also decreases with the level of dissonance (MM2 and MM3). Although many of these statistical associations are only significant at the $10 \%$ level, they suggest that mis-

\footnotetext{
${ }^{6}$ In the tables presenting the modeling results (discussed in the next section), the variables that have been shown in the referenced paper to affect the extent and level of neighborhood type dissonance empirically using the same data are marked.
} 
Table 3

The relationship between total weekly distance traveled (in miles) and presence and extent of residential neighborhood dissonance, by residential neighborhood

\begin{tabular}{|c|c|c|c|c|c|c|c|}
\hline & \multicolumn{2}{|c|}{ North San Francisco } & \multicolumn{2}{|c|}{ Pleasant Hill } & \multicolumn{2}{|l|}{ Concord } \\
\hline & & Average & $n$ cases & Average & $n$ cases & Average & $n$ cases \\
\hline \multirow[t]{2}{*}{ MM1 } & 0 (consonant) & 156.4 & 509 & 264.8 & 266 & 252.3 & 251 \\
\hline & 1 (dissonant) & 166.2 & 158 & 267.4 & 97 & 263.1 & 58 \\
\hline \multirow[t]{4}{*}{ MM3 } & 0 (consonant) & 157.0 & 505 & 265.6 & 262 & $252.8^{\mathrm{a}}$ & 250 \\
\hline & 1 (dissonant) & 168.1 & 83 & 239.6 & 44 & 228.6 & 25 \\
\hline & 2 (more dissonant) & 170.6 & 56 & 298.7 & 41 & 260.0 & 26 \\
\hline & 3 (most dissonant) & 130.4 & 14 & 273.8 & 11 & 397.9 & 7 \\
\hline \multirow[t]{3}{*}{ MM5 } & 0 (consonant) & 157.2 & 566 & 265.3 & 309 & 251.8 & 257 \\
\hline & 1 (dissonant) & 167.7 & 101 & 266.4 & 54 & 266.4 & 52 \\
\hline & & \multicolumn{6}{|c|}{ Correlation w. total miles } \\
\hline \multicolumn{2}{|l|}{ MM2 } & \multicolumn{2}{|l|}{0.045} & \multicolumn{2}{|l|}{-0.011} & \multicolumn{2}{|l|}{0.045} \\
\hline \multicolumn{2}{|l|}{ MM4 } & \multicolumn{2}{|l|}{0.011} & 0.061 & & \multicolumn{2}{|l|}{0.101} \\
\hline
\end{tabular}

${ }^{a}$ Kruskal-Wallis test yields statistically significant within-neighborhood differences with $p<0.10$.

matched urban residents tend to travel more by private car and less by alternative modes than true urbanites.

Statistically significant relationships between the presence and extent of mismatch and distance traveled by transportation modes are rather scarce among suburban respondents and limited to the bus and rail modes. For Concord residents positive correlations exist between the degree of dissonance (MM2 and MM4) and distance traveled by rail and bus, respectively (indicating that mismatched Concord residents tend to use transit more than their true suburbanite neighbors). The Kruskal-Wallis tests for the relation between MM3 and the distance by bus also render statistically significant differences for Concord and Pleasant Hill. This is, however, because in both instances there is one group of dissonant respondents who do not travel by bus at all.

This last result illustrates that investigating the distance by a specific mode for all respondents residing in a neighborhood entails the joint analysis of the related decisions of whether or not to use the mode in question, and the conditional decision about the actual mileage (see Section 3 ). For MM5 Fig. 3 shows that the decision about whether or not to use rail or bus at all is strongly dependent on whether a person is mismatched or not in each of the three neighborhoods investigated. In contrast, differences in the use of the private vehicle and walking/jogging/bicycling vary much less with the existence of neighborhood type dissonance. In fact, statistically significant (at the 5\% level) within-neighborhood differences in shares of users between consonant and dissonant respondents are limited to the bus and rail modes: rail use in Concord and North San Francisco and bus use in Pleasant Hill and North San Francisco. It thus appears that the differences for the private vehicle and walking/jogging/bicycling in Table 4 are mainly due to the conditional decisions about travel distance, while both the decision of using a mode or not and the conditional distance decision are important in explaining the differences for rail and bus. 
Table 4

The relationship between weekly distance traveled by mode (in miles) and the presence and extent of residential neighborhood dissonance, by residential neighborhood

\begin{tabular}{|c|c|c|c|c|c|c|c|c|c|c|c|c|c|}
\hline & \multicolumn{3}{|c|}{ Private vehicle } & \multicolumn{3}{|l|}{ Rail } & \multicolumn{3}{|l|}{ Bus } & \multicolumn{3}{|c|}{ Walking/jogging/bicycling } \\
\hline & & $\begin{array}{l}\text { North } \\
\text { San } \\
\text { Francisco }\end{array}$ & $\begin{array}{l}\text { Pleasant } \\
\text { Hill }\end{array}$ & $\begin{array}{l}\text { Con- } \\
\text { cord }\end{array}$ & $\begin{array}{l}\text { North } \\
\text { San } \\
\text { Francisco }\end{array}$ & $\begin{array}{l}\text { Pleasant } \\
\text { Hill }\end{array}$ & $\begin{array}{l}\text { Con- } \\
\text { cord }\end{array}$ & $\begin{array}{l}\text { North } \\
\text { San } \\
\text { Francisco }\end{array}$ & $\begin{array}{l}\text { Pleasant } \\
\text { Hill }\end{array}$ & $\begin{array}{l}\text { Con- } \\
\text { cord }\end{array}$ & $\begin{array}{l}\text { North } \\
\text { San } \\
\text { Francisco }\end{array}$ & $\begin{array}{l}\text { Pleasant } \\
\text { Hill }\end{array}$ & $\begin{array}{l}\text { Con- } \\
\text { cord }\end{array}$ \\
\hline \multicolumn{14}{|c|}{ Average weekly distance traveled } \\
\hline \multirow[t]{2}{*}{ MM1 } & 0 (consonant) & 114.8 & 223.2 & 210.0 & 7.7 & 21.0 & 23.0 & $13.3^{\mathrm{a}}$ & 0.4 & 0.6 & 12.1 & 8.0 & 6.3 \\
\hline & 1 (dissonant) & 134.7 & 219.6 & 207.1 & 4.3 & 25.9 & 32.5 & 7.6 & 0.6 & 1.2 & 10.4 & 7.7 & 7.3 \\
\hline \multirow[t]{4}{*}{ MM3 } & 0 (consonant) & $115.6^{\mathrm{b}}$ & 223.5 & 210.4 & $7.7^{\mathrm{b}}$ & 21.3 & 23.1 & $13.3^{\mathrm{b}}$ & $0.4^{\mathrm{c}}$ & $0.6^{\mathrm{c}}$ & $12.0^{\mathrm{b}}$ & 8.0 & 6.3 \\
\hline & 1 (dissonant) & 134.5 & 187.4 & 21.8 & 5.1 & 26.0 & 16.9 & 8.0 & 0.8 & 0.5 & 10.0 & 8.0 & 7.0 \\
\hline & 2 (more dissonant) & 136.9 & 247.4 & 190.5 & 4.4 & 30.0 & 46.2 & 7.8 & 0.6 & 0.0 & 11.1 & 8.7 & 8.0 \\
\hline & 3 (most dissonant) & 119.7 & 249.6 & 255.7 & 0.2 & 13.7 & 40.0 & 6.9 & 0.0 & 8.6 & 11.9 & 4.4 & 5.8 \\
\hline \multirow[t]{2}{*}{ MM5 } & 0 (consonant) & 117.3 & 222.7 & 211.6 & 7.0 & 21.9 & 22.7 & $12.6^{\mathrm{d}}$ & 0.4 & 0.6 & 11.9 & 8.0 & 6.3 \\
\hline & 1 (dissonant) & 131.7 & 219.4 & 199.1 & 6.0 & 24.5 & 36.9 & 8.7 & 0.6 & 1.4 & 10.5 & 7.5 & 7.6 \\
\hline \multicolumn{14}{|c|}{ Correlation with distance } \\
\hline \multicolumn{2}{|c|}{ MM2 } & 0.081 & -0.042 & -0.036 & -0.114 & 0.051 & 0.166 & -0.142 & 0.088 & 0.110 & -0.078 & -0.005 & 0.089 \\
\hline \multicolumn{2}{|l|}{ MM4 } & 0.043 & 0.029 & -0.020 & $-0.100^{*}$ & 0.069 & $0.168^{* *}$ & $-0.099^{* *}$ & 0.091 & $0.163^{* *}$ & -0.040 & -0.007 & 0.073 \\
\hline
\end{tabular}

Note: The numbers of cases per neighborhood type dissonance category are identical to those shown in Table 3.

${ }^{*} p<0.10$.

** $p<0.05$.

a Kruskal-Wallis test yields statistically significant within-neighborhood differences with $p<0.10$.

b $t$-Test yields statistically significant within-neighborhood differences with $p<0.10$.

c $t$-Test yields statistically significant within-neighborhood differences with $p<0.05$.

d Kruskal-Wallis test yields statistically significant within-neighborhood differences with $p<0.05$. 


\section{Models of distance traveled}

\subsection{Distance traveled overall}

Because all respondents engage in some travel, standard tobit models without a correction for selectivity bias have been specified and estimated (Table 5). In keeping with the descriptive results of Table 3, the baseline model shows that respondents in North San Francisco travel significantly less than their suburban counterparts. As hypothesized, mismatched urban residents travel statistically longer distances (only at $p=0.081$ ) than true urbanites but shorter distances than suburban respondents. The impact of the level of mismatch is limited to urban respondents; for Pleasant Hill or Concord none of the mismatch indicators yielded statistically significant results. However, as Fig. 4 shows, the impact of mismatch, even for the most extreme measure (MM5), does not outweigh that of residential location. The baseline model predicts that the average true urbanite travels 96.0 miles per week, while the average dissonant urban dweller covers 112.7 miles or $+17 \%$ when compared to the true urbanite. The average suburban respondent (whether dissonant or consonant, since no mismatch indicators were significant for suburban dwellers) travels 181.7 miles, which is $89 \%$ more than the true urbanite. Thus, the impact of land use preferences is much smaller than that of the physical attributes of the neighborhood. Further, the group of people for whom land use preferences have a significant impact at all is relatively small-limited only to urban dwellers, and in particular to urban dwellers having the most extreme degrees of mismatch.

The outcomes are essentially retained once other factors are controlled. The impact of MM5 is again restricted to North San Francisco and is statistically significant at $p=0.083$. We can thus conclude that the association between mismatch and overall distance traveled is hardly affected when other variables determining distance and the degree of neighborhood type dissonance are taken into account.

The other coefficients in the full model are consistent with expectations. Part-time employed and older respondents, women except for those living alone, those with fewer cars and lower incomes, those considering travel more stressful and those advocating pro-environmental policies travel fewer miles. In contrast, those with an occupation in sales, adventure seekers, and workaholics tend to travel more. The pseudo- $R^{2}$ statistics suggest that the models explain a fair share of the variation in total weekly distance, comparable to or better than many disaggregate models of travel behavior in the literature.

\subsection{Distance by private vehicle}

Because almost all respondents engage in vehicle travel, regular tobit models have also been specified for this variable (Table 5). The baseline model yields results comparable to those for distance overall: mismatched urban residents (now represented by MM1) travel more than true urbanites but (much) less than respondents residing in Concord or Pleasant Hill. Again the impact of neighborhood type dissonance is restricted to urban North San Francisco.

Unlike the results for distance overall, the impact of dissonance becomes insignificant if travel attitudes are allowed to be included in the model. The modeling process made clear that this is specifically caused by the introduction of the pro-environmental solutions factor, which is negatively 
Table 5

Tobit regression models for total weekly distance traveled and distance by private vehicle

\begin{tabular}{|c|c|c|c|c|c|c|c|c|}
\hline & \multicolumn{4}{|c|}{ Log total miles } & \multicolumn{4}{|c|}{ Log miles by private vehicle } \\
\hline & \multicolumn{2}{|c|}{ Baseline model } & \multicolumn{2}{|l|}{ Full model } & \multicolumn{2}{|c|}{ Baseline model } & \multicolumn{2}{|l|}{ Full model } \\
\hline & Coef. & $t$-Value & Coef. & $t$-Value & Coef. & $t$-Value & Coef. & $t$-Value \\
\hline $\begin{array}{l}\text { Neighborhood type dissonance } \\
\text { MM1 for NSF resident } \\
\text { MM5 for NSF resident }\end{array}$ & 0.160 & 1.74 & 0.154 & 1.73 & 0.364 & 4.16 & & \\
\hline $\begin{array}{l}\text { Residential location and vehicl } \\
\text { NSF resident } \\
\text { Ratio of vehicles to valid } \\
\text { driver's licenses }\end{array}$ & $\begin{array}{r}\text { ownership } \\
-0.638\end{array}$ & -13.30 & $\begin{array}{r}-0.645 \\
0.129\end{array}$ & $\begin{array}{r}-12.19 \\
2.69\end{array}$ & -1.495 & -13.57 & $\begin{array}{r}-0.769 \\
0.680\end{array}$ & $\begin{array}{r}-9.89 \\
8.44\end{array}$ \\
\hline $\begin{array}{l}\text { Mobility constraints } \\
\text { Driving at night } \\
\text { Using public transit }^{\mathrm{b}}\end{array}$ & & & & & & & $\begin{array}{r}-0.439 \\
0.320\end{array}$ & $\begin{array}{r}-2.99 \\
2.01\end{array}$ \\
\hline $\begin{array}{l}\text { Sociodemographic variables } \\
\text { Household income } \\
\quad(1000 \text { US } \$)^{\mathrm{a}, \mathrm{b}}\end{array}$ & & & 0.005 & 6.49 & & & 0.008 & 5.98 \\
\hline $\begin{array}{l}\text { Part-time employed } \\
\text { Occupation in sales } \\
\text { Female } \\
\text { Single working female } \\
\text { One-worker family } \\
\text { Multiple adults and workers } \\
\text { Number of persons with } \\
\quad \text { valid driver's license } \\
\text { Age (in years) }\end{array}$ & & & $\begin{array}{r}-0.138 \\
0.219 \\
-0.285 \\
0.294 \\
0.276\end{array}$ & $\begin{array}{r}-2.24 \\
2.90 \\
-5.97 \\
3.89 \\
2.84\end{array}$ & & & $\begin{array}{r}-0.193 \\
0.367 \\
-0.177 \\
0.283 \\
0.498 \\
-0.268 \\
0.137\end{array}$ & $\begin{array}{r}-1.98 \\
3.03 \\
-2.33 \\
2.18 \\
3.21 \\
-1.77 \\
2.65\end{array}$ \\
\hline $\begin{array}{l}\text { Lifestyle and personality facto } \\
\text { Adventure seeker factor }{ }^{\mathrm{b}} \\
\text { Workaholic factor }{ }^{\mathrm{b}}\end{array}$ & & & $\begin{array}{l}0.095 \\
0.068\end{array}$ & $\begin{array}{l}3.60 \\
2.38\end{array}$ & & & 0.098 & 2.40 \\
\hline $\begin{array}{l}\text { Travel attitudes } \\
\text { Travel stress factor } \\
\text { Travel freedom factor } \\
\text { Pro-env. solutions factor } \\
\text { Liking for travel on a bus }\end{array}$ & & & $\begin{array}{r}-0.063 \\
-0.065 \\
0.060\end{array}$ & $\begin{array}{r}-2.16 \\
-2.21 \\
2.50\end{array}$ & & & $\begin{array}{r}0.231 \\
-0.235\end{array}$ & $\begin{array}{r}4.50 \\
-5.32\end{array}$ \\
\hline $\begin{array}{l}\text { Constant } \\
\sigma\end{array}$ & $\begin{array}{l}5.36 \\
0.812\end{array}$ & $\begin{array}{r}166.17 \\
49.96\end{array}$ & $\begin{array}{l}5.103 \\
0.744\end{array}$ & $\begin{array}{l}38.41 \\
49.96\end{array}$ & $\begin{array}{l}5.108 \\
1.342\end{array}$ & $\begin{array}{l}95.79 \\
48.42\end{array}$ & $\begin{array}{l}3.562 \\
1.187\end{array}$ & $\begin{array}{l}13.61 \\
48.45\end{array}$ \\
\hline$N$ observations & 1248 & & 1248 & & 1247 & & 1247 & \\
\hline $\begin{array}{l}\text { Log likelihood } \\
\text { (constant only) }\end{array}$ & -1595.1 & & -1595.1 & & -2251.4 & & -2251.4 & \\
\hline Log likelihood (convergence) & -1510.4 & & -1401.5 & & -2134.6 & & -1981.7 & \\
\hline Model improvement $\left(\chi^{2}\right)$ & 169.4 & & 398.2 & & 233.6 & & 539.2 & \\
\hline Likelihood ratio index & 0.053 & & 0.121 & & 0.052 & & 0.120 & \\
\hline McKelvey-Zavoina $R^{2}$ & 0.106 & & 0.213 & & 0.221 & & 0.391 & \\
\hline
\end{tabular}

${ }^{\text {a }}$ Category midpoint used as estimate of true value.

b Variable known to influence the extent of residential neighborhood type mismatch (see Schwanen and Mokhtarian, 2004). 


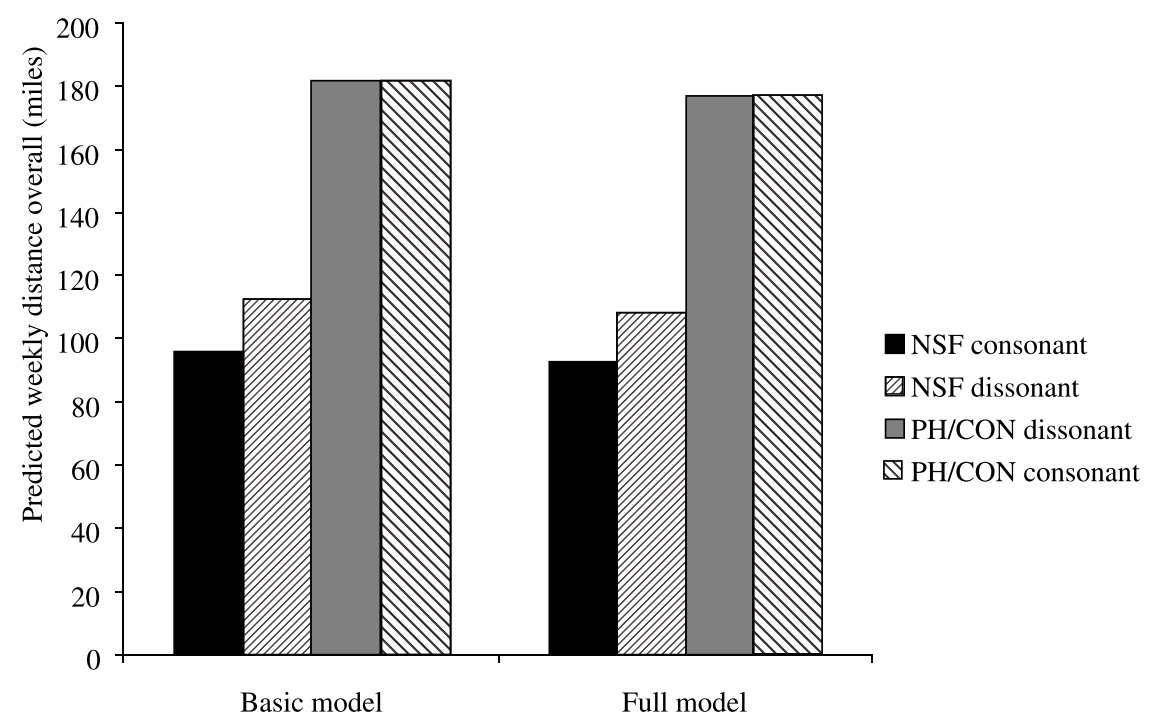

$\mathrm{NSF}=$ North San Francisco $; \mathrm{PH}=$ Pleasant Hill $; \mathrm{CON}=$ Concord

Fig. 4. Predicted weekly distance traveled overall according to the baseline and full tobit models, for an average resident in each category, by residential neighborhood and residential neighborhood type dissonance (MM5).

related to the distance by private vehicle, as well as to the mismatch indicator MM1 $(r=-0.09$ for the 1358 commuters in the sample). The latter is no surprise, given that the pro-environmental solutions factor and pro-high density factor on which the mismatch indicators were based were derived in the same oblique-rotation factor analysis. Nonetheless, because the pair-wise correlation is not very strong and because the impact of dissonance was not reduced much after the pro-environmental solutions factors entered the model for distance overall, it appears that the relationships may be complex and partly indirect. Workers with a positive score on this factor believe that the adverse environmental consequences of vehicle travel should be moderated through the pricing of auto use, introduction of clean-fuel vehicles, and promotion of public transit (Mokhtarian et al., 2001; Redmond, 2000). Thus, it is reasonable that a strong pro-environmental attitude would at least somewhat reduce the auto distance traveled - although a number of studies such as Fujii et al. (2001) and Hagman (2003) have shown that such attitudes do not always translate to congruent behavior. In view of that, we infer that for distance traveled by private vehicle the travel-related attitudes appear to be more important than the influence of neighborhood type dissonance.

The remainder of the full specification resembles that for distance overall in many respects, revealing the extremely dominant role of the automobile in overall travel patterns even in the transit-friendly Bay Area. In terms of model performance, the McKelvey-Zavoina $R^{2}$ statistics are substantially higher for distance traveled by private vehicle than for distance overall.

\subsection{Distance by rail}

For this measure of distance traveled the complete tobit model system has been estimated (Table 6). As the baseline specification shows, the decisions modeled are clearly influenced by a 
Table 6

Tobit model system for weekly distance traveled by rail

\begin{tabular}{|c|c|c|c|c|c|c|c|c|}
\hline & \multicolumn{4}{|c|}{ Baseline model } & \multicolumn{4}{|l|}{ Full model } \\
\hline & \multicolumn{2}{|c|}{ Selection (use) } & \multicolumn{2}{|c|}{$\begin{array}{l}\text { Regression } \\
\text { (distance) }\end{array}$} & \multicolumn{2}{|c|}{ Selection (use) } & \multicolumn{2}{|c|}{$\begin{array}{l}\text { Regression } \\
\text { (distance) }\end{array}$} \\
\hline & Coef. & $t$-Value & Coef. & $t$-Value & Coef. & $t$-Value & Coef. & $t$-Value \\
\hline \multicolumn{9}{|l|}{ Neighborhood type dissonance } \\
\hline MM2 for NSF resident & -0.567 & -7.35 & & & -0.343 & -5.26 & & \\
\hline MM5 for NSF resident & & & 0.871 & 1.96 & & & & \\
\hline MM4 for PH resident & 0.130 & 3.08 & & & & & & \\
\hline MM4 for CON resident & 0.189 & 4.18 & & & & & & \\
\hline MM5 for suburban resident & & & & & & & -1.234 & -4.10 \\
\hline \multicolumn{9}{|c|}{ Residential location and vehicle ownership } \\
\hline NSF resident & 0.795 & 7.44 & -2.037 & -9.29 & & & -2.041 & -9.42 \\
\hline $\begin{array}{l}\text { Ratio of vehicles to valid } \\
\text { driver's licenses }^{\mathrm{a}}\end{array}$ & & & & & -0.405 & -5.60 & & \\
\hline \multicolumn{9}{|l|}{ Mobility constraints } \\
\hline Bicycling $^{\mathrm{a}}$ & & & & & 0.233 & 2.36 & & \\
\hline \multicolumn{9}{|l|}{ Sociodemographics } \\
\hline Occupation in services & & & & & -0.575 & -3.03 & & \\
\hline $\begin{array}{l}\text { Occupation in production/ } \\
\text { construction/crafts }\end{array}$ & & & & & -0.578 & -2.56 & & \\
\hline Professional/technical occupation & & & & & & & 0.296 & 1.81 \\
\hline One-worker family & & & & & -0.731 & -3.76 & & \\
\hline Female in multiple-worker family & & & & & -0.295 & -2.72 & & \\
\hline \multicolumn{9}{|l|}{ Personality and lifestyle factors } \\
\hline Status seeker factor ${ }^{\mathrm{a}}$ & & & & & & & -0.232 & -2.06 \\
\hline Frustrated factor & & & & & & & 0.201 & 2.04 \\
\hline \multicolumn{9}{|l|}{ Travel attitudes } \\
\hline Pro-env. solutions factor & & & & & 0.333 & 7.16 & & \\
\hline Liking for traveling by rail & & & & & 0.186 & 4.78 & & \\
\hline Constant & 1.088 & -15.08 & 5.857 & 9.71 & -1.083 & -6.19 & 4.770 & 12.76 \\
\hline$\sigma$ & & & 1.573 & 7.45 & & & 1.306 & 16.60 \\
\hline$\rho$ & & & -0.637 & -3.41 & & & -0.245 & -1.40 \\
\hline$N$ observations & 1353 & & & & 1353 & & & \\
\hline Log likelihood (constant only) ${ }^{\mathrm{b}}$ & -1316.8 & & & & -1316.8 & & & \\
\hline Log likelihood (convergence) & -1157.8 & & & & -1009.3 & & & \\
\hline Model improvement $\left(\chi^{2}\right)$ & 318.0 & & & & 615.0 & & & \\
\hline $\begin{array}{l}\text { Likelihood ratio index } \\
\text { (model system) }\end{array}$ & 0.121 & & & & 0.234 & & & \\
\hline $\begin{array}{l}\text { Likelihood ratio index (selection } \\
\text { model estimated separately) }\end{array}$ & 0.285 & & & & 0.354 & & & \\
\hline
\end{tabular}

\footnotetext{
${ }^{a}$ Variable known to influence the extent of residential neighborhood type mismatch (see Schwanen and Mokhtarian, 2004).

${ }^{\mathrm{b}}$ Estimate for a regular tobit model without selection equation (see Footnote 3 to the text).
} 
worker's residential location and neighborhood type mismatch. Turning first to the selection model, the residential location dummy variable shows that the tendency to use rail is higher in North San Francisco, but this effect is to a substantial degree offset by MM2: for more than half of the urban respondents (the most dissonant) the net effect of the two variables is negative. The baseline selection model also contains two dissonance indicators for Pleasant Hill and Concord, suggesting that mismatched suburban residents are more likely to use rail. This effect is stronger for Concord, which may reflect that this is the more 'suburban' of the two communities in the sense that building densities are lower there than in Pleasant Hill (Table 1).

These results support the notion of a continuum with the lowest probability of using rail for true suburbanites, an intermediate chance for mismatched suburban and mismatched urban residents, and the highest likelihood for consonant urban residents. A similar hierarchy albeit in reverse order can be discerned for the distance traveled by rail: The distance is shortest among true urbanites and longest among suburban residents with dissonant urban residents in between those scores. The change of the signs for the residential location and mismatch variables between the decision to use rail and the distance traveled indicates the importance of not restricting the sign of independent variables to be equal across the two behavioral dimensions as in the standard tobit model (Section 3). The reason for the difference in signs presumably lies in the geography of the rail network and of the regional location patterns: suburban residents may be less rail-oriented on average than urban residents, but those suburban residents who are rail-oriented have longer distances to travel (e.g., to a job in the central business district) than do more centrally-located urban residents.

Once other explanatory variables are allowed to enter the models, the influence of neighborhood type dissonance becomes considerably smaller. In the full model selection equation only one dissonance term is included, showing that the proclivity of using rail decreases, as the level of mismatch experienced by an urban resident is larger. During the modeling process it became clear that this reduction in the influence of mismatch is due to the inclusion of the pro-environmental solutions factor, which is positively correlated with the propensity to use rail. In terms of distance traveled by rail, the full specification indicates that urban residents cover the shortest distance and true suburbanites the longest, with mismatched suburbanites falling in between these extremes.

The results for the remaining variables are largely as expected. The likelihood of using rail is lower as a household has more vehicles available, and for workers employed in services or production/construction/crafts, females in multiple-worker families, and in one-worker families. It is higher as workers have a stronger affinity with rail and experience problems with bicycling. With respect to the actual distance traveled, the models show that workers in technical/professional occupations, the more frustrated and the less status-seeking individuals tend to cover greater distances.

The correlation coefficient $\rho$ is negative in both models, indicating that not only some observed variables, but also unobserved, variables have opposite effects on use and distance. The correlation is not statistically significant at the $5 \%$ level in the full model, suggesting that the decision to use rail and the decision about distance traveled could have been modeled independently without resulting in biased coefficients. We nevertheless present the more complicated model system because the negative correlation coefficient suggests that we may still be missing some attitudinal variables that are relevant to the explanation of both the choice to use rail and the distance 
Table 7

Tobit model system for distance traveled by bus

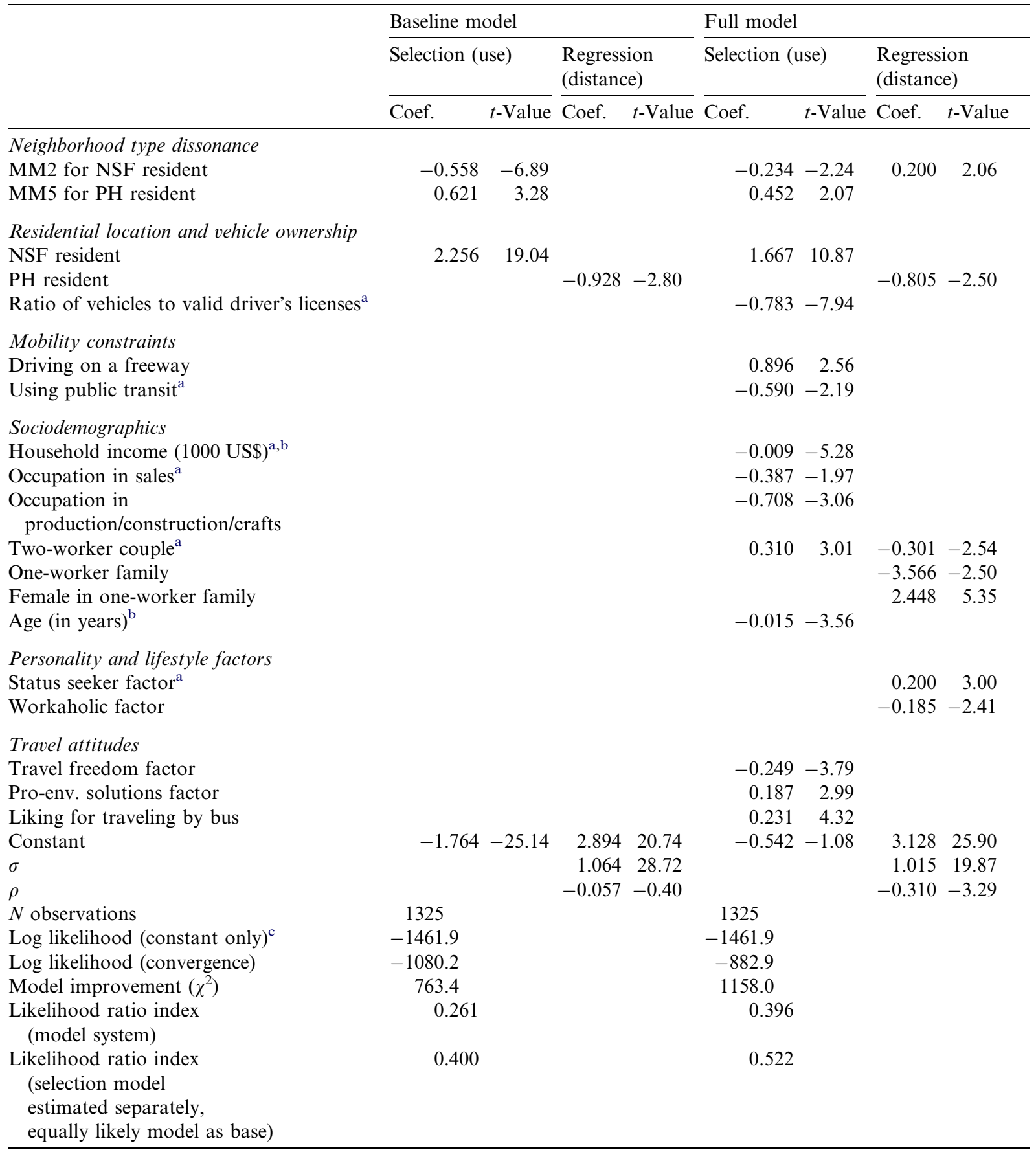

${ }^{\text {a }}$ Variable known to influence the extent of residential neighborhood type mismatch (see Schwanen and Mokhtarian, 2004).

${ }^{\mathrm{b}}$ Category midpoint used as estimate of true value.

${ }^{\mathrm{c}}$ Estimate for a regular tobit model without selection equation (see Footnote 3 to the text). 
traveled with this mode. The goodness-of-fit measures indicate that the full tobit model system performs much better than the baseline specification.

\subsection{Distance by bus}

Residential location and neighborhood type dissonance are related to bus use (Table 7). Both the baseline and the full specification of the selection equation indicate that the overall probability of traveling by bus is highest among true urbanites, followed by mismatched urban residents, then by mismatched Pleasant Hill residents, and lowest among true suburbanites and mismatched Concord residents. The fact that these dissonance indicators are included in both specifications suggest that mismatch has an independent effect on the overall likelihood of traveling by bus, although the magnitude of the coefficients suggests that this impact is reduced when other determinants are included.

The baseline specification contains no effects of mismatch on distance traveled; in the full model specification an unexpected positive effect of MM2 for North San Francisco is included. This effect only shows up when other factors are taken into account, but its explanation is unclear. Perhaps the action space of these bus users is larger; while true urbanites may use the bus largely for travel within the city of North San Francisco, dissonant urban residents may use the bus to travel to suburban locations. Both specifications indicate that Pleasant Hill residents travel the shortest distance by bus conditional on the decision of using it.

The signs of the other coefficients in the full model are again as expected. The overall probability of using bus is lower, as the ratio of vehicles to drivers, the constraints on the use of transit, the score on the travel freedom factor, the household income, or the respondent's age is higher, and for workers in sales or production/construction/crafts occupations and females in one-worker families. In contrast, this likelihood is higher, as constraints on driving on the freeway, the respondent's score on the pro-environmental solutions factor, and the liking for bus travel increase. In terms of distance traveled, the coefficients indicate that conditional on using bus at all, males in one-worker families and status seekers tend to travel longer and individuals from two-worker couples and workaholics shorter distances.

The correlation coefficient $\rho$ is negative in both models, but only statistically significant in the full model. This provides further, more rigorous evidence that relevant attitudinal and other variables simultaneously affecting the use of and distance by bus are lacking from our specification. Given the rather high values for the likelihood ratio indices for the independent probit models in Table 7, it appears not very likely that the negative correlation stems from a poorly performing probit equation.

\subsection{Distance by walking/jogging/bicycling}

Residential location and neighborhood type dissonance are also associated with the use of and distance by the slow modes of transportation, as the baseline specification reveals (Table 8). North San Francisco residents overall are most likely to engage in walking/jogging/bicycling, and Concord residents the least. Urban respondents also cover larger distances by these modes than those residing in the suburbs, although this effect is reduced, as the level of mismatch is higher for urban residents. The model also suggests that clear differences exist between Concord and Pleasant Hill 
Table 8

Tobit model system for distance traveled by walking/jogging/bicycling

\begin{tabular}{|c|c|c|c|c|c|c|c|c|}
\hline & \multicolumn{4}{|c|}{ Baseline model } & \multicolumn{4}{|l|}{ Full model } \\
\hline & \multicolumn{2}{|c|}{ Selection (use) } & \multicolumn{2}{|c|}{$\begin{array}{l}\text { Regression } \\
\text { (distance) }\end{array}$} & \multicolumn{2}{|c|}{ Selection (use) } & \multicolumn{2}{|c|}{$\begin{array}{l}\text { Regression } \\
\text { (distance) }\end{array}$} \\
\hline & Coef. & $t$-Value & Coef. & $t$-Value & Coef. & $t$-Value & Coef. & $t$-Value \\
\hline MM2 for NSF resident & & & -0.149 & -2.66 & & & & \\
\hline $\begin{array}{l}\text { Residential location } \\
\text { NSF resident } \\
\text { CON resident }\end{array}$ & $\begin{array}{r}0.536 \\
-0.279\end{array}$ & $\begin{array}{r}3.56 \\
-2.10\end{array}$ & $\begin{array}{r}0.441 \\
-0.261\end{array}$ & $\begin{array}{r}5.05 \\
-3.16\end{array}$ & 0.468 & 3.59 & & \\
\hline $\begin{array}{l}\text { Sociodemographics } \\
\text { Professional/technical occupation } \\
\text { Household income (1000 US\$) } \\
\text { Female in multiple-worker family } \\
\text { 'Other' household }\end{array}$ & & & & & -0.385 & -1.92 & $\begin{array}{r}0.100 \\
-0.002 \\
-0.323\end{array}$ & $\begin{array}{r}2.14 \\
-2.79 \\
-4.56\end{array}$ \\
\hline $\begin{array}{l}\text { Personality and lifestyle factors } \\
\text { Adventure seeker factor }{ }^{\mathrm{b}} \\
\text { Frustrated factor }\end{array}$ & & & & & & & $\begin{array}{r}0.102 \\
-0.060\end{array}$ & $\begin{array}{r}3.92 \\
-2.12\end{array}$ \\
\hline $\begin{array}{l}\text { Travel attitudes } \\
\text { Pro-env. solutions factor } \\
\text { Liking for traveling } \\
\text { by personal vehicle }\end{array}$ & & & & & & & $\begin{array}{r}0.082 \\
-0.049\end{array}$ & $\begin{array}{r}2.82 \\
-1.92\end{array}$ \\
\hline Liking for traveling by bus & & & & & -0.123 & -1.90 & & \\
\hline $\begin{array}{l}\text { Liking for walking/cycling/jogging } \\
\text { Liking for traveling to eat out }\end{array}$ & & & & & 0.664 & 10.60 & $\begin{array}{r}0.348 \\
-0.074\end{array}$ & $\begin{array}{r}10.54 \\
-2.17\end{array}$ \\
\hline $\begin{array}{l}\text { Constant } \\
\sigma \\
\rho\end{array}$ & 0.838 & 8.18 & $\begin{array}{l}1.905 \\
0.910 \\
0.850\end{array}$ & $\begin{array}{l}30.56 \\
33.61 \\
16.18\end{array}$ & -1.213 & -6.51 & $\begin{array}{l}1.304 \\
0.795 \\
0.713\end{array}$ & $\begin{array}{r}6.45 \\
34.90 \\
8.39\end{array}$ \\
\hline$N$ observations & 1303 & & & & 1303 & & & \\
\hline Log likelihood (constant only) ${ }^{\mathrm{c}}$ & -2085.4 & & & & -2085.4 & & & \\
\hline Log likelihood (convergence) & -1819.3 & & & & -1650.1 & & & \\
\hline Model improvement $\left(\chi^{2}\right)$ & 532.2 & & & & 870.6 & & & \\
\hline $\begin{array}{l}\text { Likelihood ratio index } \\
\text { (model system) }\end{array}$ & 0.128 & & & & 0.209 & & & \\
\hline $\begin{array}{l}\text { Likelihood ratio index } \\
\text { (selection model } \\
\text { estimated separately, equally } \\
\text { likely model as base) }\end{array}$ & 0.399 & & & & 0.489 & & & \\
\hline
\end{tabular}

${ }^{a}$ Category midpoint used as estimate of true value.

b Variable known to influence the extent of residential neighborhood type mismatch (see Schwanen and Mokhtarian, 2004).

${ }^{\mathrm{c}}$ Estimate for a regular tobit model without selection equation (see Footnote 2 to the text).

residents. The latter are not only more likely to walk/jog/bicycle, they also cover larger distances with these non-motorized modes conditional upon their use. 
Most effects of residential neighborhood and neighborhood type dissonance disappear, once other variables are taken into account. The only difference that remains is that North San Francisco residents are more likely to engage in walking/jogging/bicycling, but distances traveled are statistically similar across all groups. This reduction in the influence of neighborhood-related variables is due to the inclusion of travel attitudes the impacts of which are very strong in this model, stronger than for the other modes. Affect for walking/jogging/bicycling is especially important: it appears in both the selection and the regression equation with large and positive coefficients. This suggests that (at least for these middle- to upper-middle-class communities), the built environment is less a factor in the decision to walk/cycle/jog (and how much to do so) than is one's affinity for those means of travel and/or recreation. But other attitude variables are also relevant. The more commuters like traveling by bus, the less likely they are to participate in walking/bicycling/jogging. Moreover, distance traveled by these slow modes is greater, as respondents more strongly favor pro-environmental policies, or more strongly dislike traveling by personal vehicle or traveling for eating outside the home.

The effects of the other variables are again largely as expected. The overall choice of walking/ jogging/bicycling is lower in 'other' households. The distance by walking/bicycling/jogging is longer among professionals, and as the score on the frustration factor is lower; it is shorter among women in multiple-worker families and as respondents have a higher household income, or have a lower score on the adventure seeker factor. The correlation coefficient $\rho$ is positive and clearly significant in both models. Thus, the unobserved factors increasing the propensity to use walking/ jogging/bicycling also result in greater travel distances covered by these modes.

\section{Conclusions}

This paper investigated to what extent a lack of congruence between physical neighborhood structure and preferences regarding land use near one's home location affects distance traveled in general and by mode, with data from one urban and two suburban neighborhoods in the San Francisco Bay Area. Although the impact of neighborhood type dissonance appeared to be small in the descriptive analysis, significant effects are found in some more detailed models. In particular, the weekly distance traveled overall and the distance by private vehicle are shortest among true urbanites and longest among consonant and dissonant suburban travelers pooled, with mismatched urban dwellers falling in between these extremes. The same hierarchy can be observed for the distance traveled by rail, conditional on the decision of using rail at all. The probability of using rail is itself also ordered systematically as hypothesized, with the highest probability among true urbanites, followed by mismatched urban dwellers, then mismatched suburban dwellers, and lowest among true suburbanites. The likelihood of using bus varies in a similar vein, but distance by bus conditional on its selection is less clearly associated with residential neighborhood and the degree of mismatch. For walking/bicycling/jogging we found that urban residents are most likely to use these modes, but that the conditional distance covered is influenced more by the liking for such activities than by the neighborhood or mismatch indicators. The models made clear that, even after numerous other factors including attitudes toward modes are taken into account, the level of neighborhood type mismatch continues to affect distance traveled overall as well as by rail and bus. One of the implications of this finding is that studies of residential 
self-selection with respect to travel behavior should not limit their focus to attitudes toward modes but incorporate a wider set of preference indicators including those pertaining to land use.

While neighborhood type dissonance is included in most models, the physical land use structure appears to exert a stronger influence on distance traveled than do preferences toward land use. Residential self-selection processes thus seem to affect the land use-travel behavior link-but only to a certain degree. Additionally, neighborhood type mismatch matters more often for urban than for suburban residents. Although mismatched suburban residents may be more inclined to travel less in general and in particular by private vehicle, many may feel they have little choice: land use patterns imply that distances to potential destinations are quite large, and public transit services may not be compatible with lifestyle constraints. In urban North San Francisco the situation is different. Mismatched residents may be inclined to make more use of the private vehicle mode, and many of them do. In short, if you prefer a suburban lifestyle but live in the 'wrong' neighborhood, you are better capable of realizing your preferred type of travel than if you prefer urban life but reside in the 'wrong' type of place.

\section{Acknowledgments}

The University of California Transportation Center funded the collection of the data, with further analysis also supported by the Daimler-Chrysler Corporation. Part of the work was carried out when the first author visited the Institute of Transportation Studies of the University of California, Davis in a visit sponsored by a SYLFF grant from the Tokyo Foundation with additional subsidy from the Travel Fund of the Netherlands Organization for Scientific Research. Comments of the two anonymous reviewers and Ken Button have substantially improved the paper.

\section{References}

Babbie, E., 1998. The Practice of Social Research. Wadsworth, Belmont, California.

Bagley, M.N., Mokhtarian, P.L., 2002. The impact of residential neighborhood type on travel behavior: a structural equations modeling approach. Annals of Regional Science 36, 279-297.

Bhat, C.R., 1997. Work travel mode and number of non-work commute stops. Transportation Research B 31, 41-54.

Boarnet, M.G., Crane, R., 2001. Travel by Design: the Influence of Urban Form on Travel. Oxford University Press, Oxford.

Cervero, R., 1996. Mixed land uses and commuting: evidence from the American Housing Survey. Transportation Research A 30, 361-377.

Cervero, R., Duncan, M., 2002. Residential Self Selection and Rail Commuting: a Nested Logit Analysis. University of California Transportation Center, Berkeley, available from: http://www.uctc.net/papers/604.pdf.

Curry Jr., R.W., 2000. Attitudes toward Travel: the Relationships among Perceived Mobility, Travel Liking, and Relative Desired Mobility. Master's Thesis, Department of Civil and Environmental Engineering, University of California, Davis. Available from: <http://www.its.ucdavis.edu/publications/2000/RR-00-06.pdf>.

Ermisch, J.F., Wright, R.E., 1994. Interpretation of negative sample selection effects in wage offer equations. Applied Economic Letters 1, 187-189.

Fujii, S., Gärling, T., Kitamura, R., 2001. Changes in drivers' perceptions and use of public transport during a freeway closure. Environment and Behavior 33, 796-808.

Greene, W.H., 2002LIMDEP Econometric Modeling Guide, vol. 2. Econometric Software, Inc., Plainview, New York. 
Hagman, O., 2003. Mobilizing meanings of mobility: car users' constructions of the goods and bads of car use. Transportation Research D 8, 1-9.

Handy, S.L., 1996. Urban form and pedestrian choices: study of Austin neighborhoods. Transportation Research Record 1552, 135-144.

Kitamura, R., 1984. A model of daily time allocation to discretionary out-of-home activities and trips. Transportation Research B 18, 255-266.

Kitamura, R., Mokhtarian, P.L., Laidet, L., 1997. A micro-analysis of land use and travel in five neighborhoods in the San Francisco Bay Area. Transportation 24, 125-158.

Krizek, K.J, 2003. Residential relocation and changes in urban travel: does neighborhood-scale urban form matter? Journal of the American Planning Association 69, 265-281.

McDonald, J.F., Moffitt, R.A., 1980. The uses of tobit analysis. Review of Economics and Statistics 62, 318-321.

Mokhtarian, P.L., Salomon, I., Redmond, L.S., 2001. Understanding the demand for travel: it's not purely 'derived'. Innovation 14, 355-380.

Pushkarev, B.S., Zupan, J.M., 1977. Public Transportation and Land Use Policy. Indiana University Press, Bloomington.

Redmond, L.S., 2000. Identifying and Analyzing Travel-related Attitudinal, Personality, and Lifestyle Clusters in the San Francisco Bay Area. Master's Thesis, Transportation Technology and Policy Graduate Group, Institute of Transportation Studies, University of California, Davis. Available from: < http://repositories.cdlib.org/itsdavis/ UCD-ITS-RR-00-08>.

Salomon, I., Ben-Akiva, M., 1983. The use of the life-style concept in travel demand models. Environment and Planning A 15, 623-638.

Schwanen, T., Mokhtarian, P.L., 2004. The extent and determinants of dissonance between actual and preferred residential neighborhood type. Environment and Planning B: Planning and Design 31, 759-784.

Schwanen, T., Mokhtarian, P.L., 2005. What affects commute mode: neighborhood physical structure or preferences toward neighborhoods? Journal of Transport Geography (forthcoming).

Sermons, M.W., Seredich, N., 2001. Assessing traveler responsiveness to land and location based accessibility and mobility solutions. Transportation Research D 6, 417-428.

Sommer, B., Sommer, R., 1997. A Practical Guide to Behavioral Research: Tools and Techniques. Oxford University Press, New York.

Stead, D., 2001. Relationships between land use, socioeconomic factors, and travel patterns in Britain. Environment and Planning B: Planning and Design 28, 499-528.

Veall, M.R., Zimmerman, K.F., 1994. Goodness of fit measures in the tobit model. Oxford Bulletin of Economics and Statistics 56, 485-499. 